\title{
Nanocars based on Polyaromatic or Porphyrinic Chassis
}

\author{
Toshio Nishino ${ }^{1}$, Colin J. Martin ${ }^{1}$, Kazuma Yasuhara ${ }^{1}$, and Gwénaël Rapenne ${ }^{1,2 *}$ \\ 1 * Division of Materials Science, Nara Institute of Science and Technology, NAIST \\ 8916-5 Takayama-cho, Ikoma, Nara 630-0192, Japan \\ ${ }^{2 *}$ CEMES, Université de Toulouse, CNRS \\ 29 rue Marvig, F-31055 Toulouse Cedex 4, France
}

(Received May 7, 2021; E-mail: gwenael-rapenne@ms.naist.jp)

\begin{abstract}
This paper is dedicated to Prof; Kazushi Kinbara who kindly invited us to be part of the "Molecular Engine" innovative areas research project.
\end{abstract}

\begin{abstract}
In this account, we describe our achievements in the field of technomimetic synthetic nanovehicles from the first synthetic nanovehicle, a wheelbarrow with two wheels, to the nanocar which qualified for the $2^{\text {nd }}$ Nanocar Race. The architecture of these nanovehicles is based on a polyaromatic or phorphyrinic chassis with ethynyltriptycenyl moiety used as wheels. The rigid and planar chassis also provides us with a potential cargo platform able to transport atoms or small molecules on surfaces.
\end{abstract}

\section{Introduction}

A nanomachine can be defined as a molecule or an assembly of molecular components designed to perform a precise function in response to a controlled stimulus. Pioneering achievements from J.-P. Sauvage, ${ }^{1}$ Sir J. F. Stoddart ${ }^{2}$ and B. L. Feringa $^{3}$ opening new perspectives in chemistry, were awarded by the Nobel prize in 2016, for their control of motions at the nanoscale consequently leading to the ultimate miniaturization of machines. Their work over the past three decades is at the origin of an incredible variety of molecular machines. Among them, some have been studied collectively in solution such as syringes, ${ }^{4}$ scissors, ${ }^{5}$ muscles, ${ }^{6}$ elevators ${ }^{7}$ or robotic arms ${ }^{8}$ while others can only be studied at the single molecular scale on an oriented medium. This is the case for instance with intermolecular gearing system ${ }^{9}$ for which the rotational motion can propagate to a neighbor only if they are maintained in close proximity. ${ }^{10}$ This is also the case for molecular vehicles, for which many kinds of surfaces can be used as a deposition substrate and near-field microscopies have been exploited both for imaging and as an energy source for manipulation.

A nanovehicle is basically a nanomachine able to move under the control of an external stimulus provided at will, with directionality at the nanoscale. In this account, we will present our contribution to this dynamic field from our first technomimetic ${ }^{11}$ prototype mimicking man-made devices with a chassis connected to wheels, the molecular wheelbarrow ${ }^{12}$ to the last generation, a family of dipolar nanocars ${ }^{13}$ ready to compete at the $2^{\text {nd }}$ Nanocar Race which could be organized in $2022 .^{14}$

\section{The Origins: Triptycene Wheel and Wheelbarrow}

\subsection{Original Question}

The synthesis of molecules equipped with wheels started during a discussion on the manipulation of planar polyaromatic molecules (landers ${ }^{15}$ ) designed to study electronic contact and conduction once in contact with a metallic surface step edge. These molecules strongly interact with metallic surfaces and one way to decrease this interaction has been to introduce four legs to alleviate the molecule from the deposition surface. But even with these legs, the molecules have been difficult to move on the surface. A physicist colleague came up with a joke which has been transformed in a new concept, to replace the legs by "wheels". After looking seriously at a promising candidate, we decided to explore the potential of triptycene ${ }^{16}$ fragments as wheel subunits and soon after, a molecular wheelbarrow was designed ${ }^{17}$ and synthesized. ${ }^{18}$

2.2 The Ethynyltriptycene Wheel

On a molecular chassis, the wheels are of course one of the key mechanical elements of a molecular vehicle. ${ }^{19}$ As on the macroscopic scale, molecular wheels allow the chassis to be elevated slightly away from the surface decreasing the lateral diffusion barrier of the nanovehicle by reducing the electronic interactions. Simple molecular legs might suffice, but in this case, movement on the surface would need a lot more energy because it would require a rocking motion from each foot to move the molecule forward. As in the macroscopic world, rotation around an axis is energetically more favorable.

As wheels, we proposed 9-ethynyltriptycene but other candidates have been tested by us and others. Tour's group used extensively [60]-fullerene ${ }^{20}$ and carboranes, ${ }^{21}$ ruthenium organometallic complexes ${ }^{22}$ and adamantanes. ${ }^{23}$ Feringa synthesized a nanovehicle with four of his famous motors as wheels $^{24}$ and Masson used cucurbituril molecules. We also explored boron-substituted subphthalocyanine ${ }^{25}$ which gave a very good contrast in the STM image at the dimer scale however the acetylenic spacer was too unstable to be incorporated into larger nanovehicles. It must be noted that some groups proposed nanocar prototypes without wheels. ${ }^{26}$ At the nanoscale, nanocar properties can be also obtained without following a technomimetic approach. All these various nanocar prototypes were able to transform electronic excitation into controlled movement.

The synthesis of the 9-ethynyltriptycene wheel was achieved in three steps from 9-bromoanthracene by coupling with a monoprotected alkyne, followed by a [4+2] addition of benzyne prepared in situ by reaction of anthranilic acid with 
isopentyl nitrite (Scheme 1).

The use of a (3-cyanopropyl) dimethylsilyl protecting group, a polar analogue of trimethylsilyl, ${ }^{27}$ allowed the easy separation of the triptycene from the unreacted anthracene. Further deprotection of the silyl group gave the desired 9ethynyltriptycene.

Scheme 1. Synthesis of the 9-ethynyltriptycene wheel.

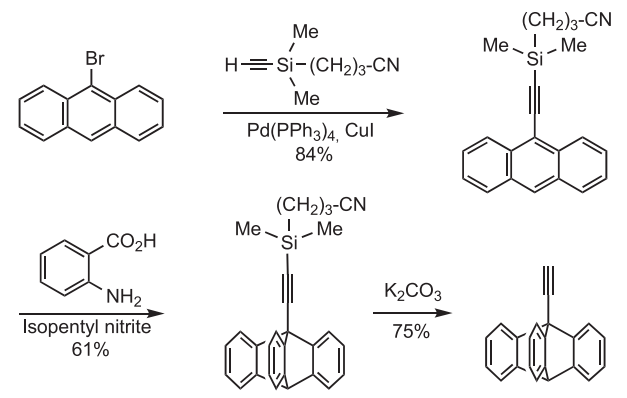

\subsection{A Molecular Wheelbarrow}

The first question which appeared was "even if the molecule can move on a surface, can we observe rotation of a wheel on a surface?" This is not a question that can be easily answered. The synthesis ${ }^{18}$ of the first molecular vehicle equipped with a chassis, two wheels at the front and two legs at the rear (Scheme 2) was published in 2003.

The wheelbarrow consists of two legs (3,5-di-tert-butylphenyl groups) and two wheels (triptycene groups) connected to a polycyclic aromatic hydrocarbon $(\mathrm{PAH})$ platform through ethynyl spacers. The two 3,5-di-tert-butylphenyl legs were shown to lie perpendicular to the main aromatic board to minimize interaction with the surface. Moreover, these alkyl substituents connected to PAHs are also useful to increase solubility in organic solvents and induce a good contrast in the image acquired by the STM. The two 9-triptycenyl wheels were able to freely rotate around the axle thanks to the acetylenic spacers. ${ }^{28}$

The synthesis was achieved in twelve steps and an overall yield of $2 \%$. As shown on Scheme 2, our strategy is based on a repetitive double Knoevenagel-Diels-Alder reaction on a diketo fragment. The first step allowed the connection of the two legs, while the second introduced two iodine atoms to provide the connection of the ethynyl triptycene wheels through a double Sonogashira coupling.

The purpose of this first vehicle was to observe the rotational movement of the two front wheels while keeping the rear part of its frame away from the surface thanks to the two rear molecular legs. The rotation of the two front wheels then had to cause a vertical back and forth movement of the front part of the chassis supporting the two axles and the wheels. When pushed back by the tip of the STM, this rocking motion should have caused a detectable oscillation in the intensity of the tunnel current passing through the wheels.

Deposition of the molecules turned out to be difficult. Sublimation was used to avoid contamination with solvents but only a few molecules survived this harsh process. ${ }^{29}$ Particularly, thermal fragmentation occurred with a high probability due to the two thermally sensitive triple bonds. However, we successfully imaged a few molecular wheelbarrows on a $\mathrm{Cu}(100)$ surface. Action of the STM tip changed the conformation but we were unable to move the molecule. ${ }^{29}$
Scheme 2. Synthesis of the first nanovehicle, a molecular wheelbarrow based on a polyaromatic hydrocarbon chassis equipped with two triptycenyl wheels. Reagents and conditions: (a) $\mathrm{KOH}, \mathrm{EtOH}$; (b) di(4-tertbutylphenyl)acetylene, $\mathrm{Ph}-\mathrm{O}-\mathrm{Ph}$; (c) benzeneseleninic anhydride, chlorobenzene; (d) 1,3-bis(4-iodophenyl)propan-2-one, $\mathrm{KOH}$, EtOH; (e) di(4-tolyl)acetylene, $\mathrm{Ph}-\mathrm{O}-\mathrm{Ph}$; (f) 9-ethynyltriptycene, $\mathrm{Pd}\left(\mathrm{PPh}_{3}\right)_{4} 10 \mathrm{~mol} \%$, $\mathrm{CuI} 20 \mathrm{~mol} \%$, piperidine-THF $(1: 1)$.
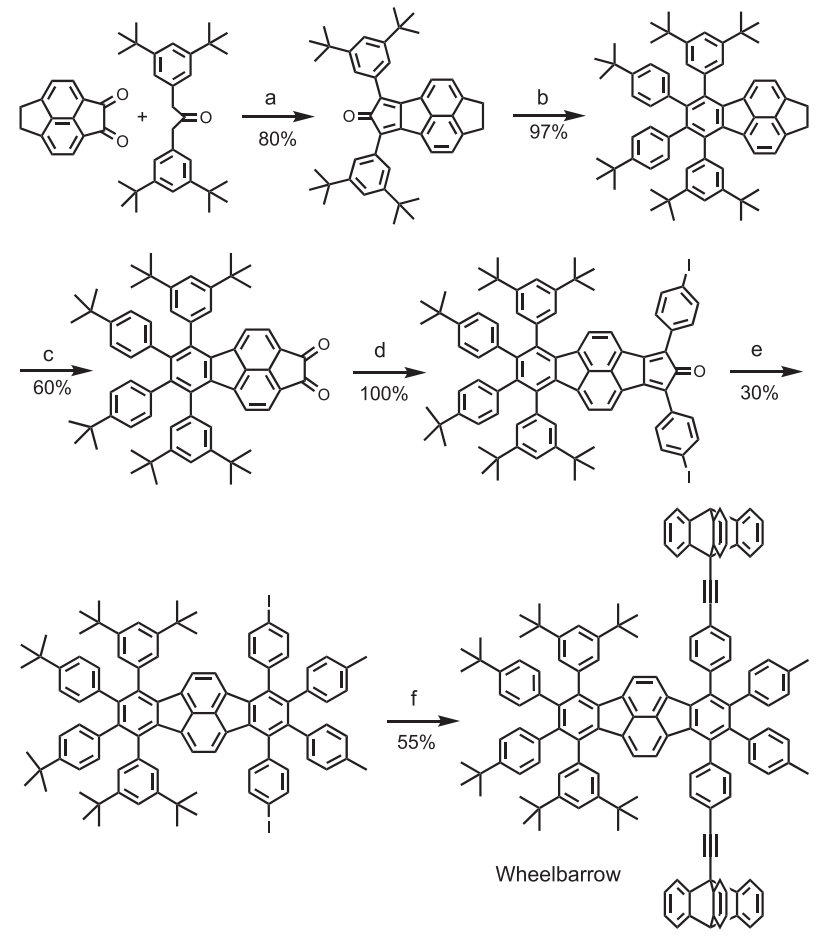

\subsection{Rotation of a Molecular Wheel on a Surface}

To study if the rotation of the wheels is possible to observe, we synthesized a dimer of wheels, a model of an axle terminated with two ethynyltriptycene wheels (Scheme 3). The dimer with a butadiyne spacer was obtained via a Glaser homocoupling of the 9-ethynyltriptycene wheel using copper(II) acetate. This model compound has been studied as prototype of a wheel dimer.

Scheme 3. Synthesis of a molecular axle with two triptycenyl wheels.

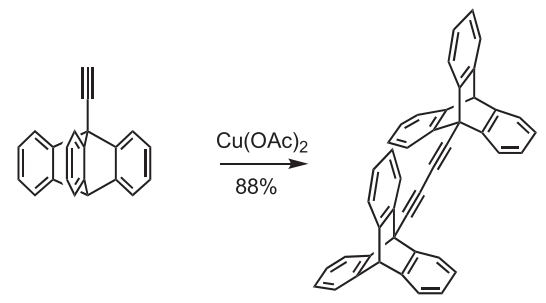

Rotation of a wheel on a surface was achieved for the first time by pushing the molecule with the STM tip at $5 \mathrm{~K}$ on $\mathrm{Cu}(111) .^{30}$ The tip was moved across the molecular axle at constant height as shown on Figure 1, and rotation proven by the study of the manipulation signal. If rotation is involved, the tunneling current recorded at constant tip height during the motion will be totally different to what is expected for the motion of the molecule without rotation. In most cases, it was possible to rotate one wheel, and in a few cases, maybe depending on the precise shape of the tip apex, the rolling motion of both wheels was observed. 


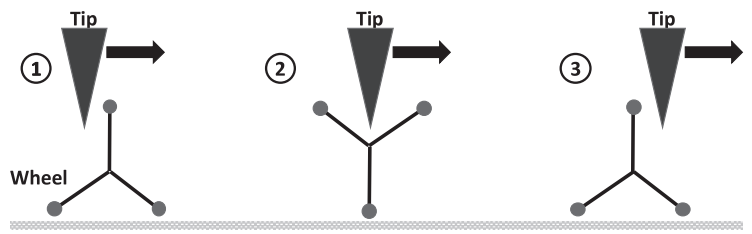

Figure 1. Rotational motion of triptycene wheels on a metallic surface. Step 1: the STM tip approaches the molecule; Step 2: the rotation of the wheel starts; Step 3: the STM tip lies on the other side of the wheel after a $120^{\circ}$ rotation.

With this rolling motion proven, four triptycene units were then integrated into the next generation of 4-wheeled nanovehicles, with the aim of increasing mobility on the surface.

\section{From Nanovehicles Equipped with Two Wheels to Four Wheels: Polyaromatic-based Nanocars}

\subsection{A Nanocar Built on a Planar Polyaromatic Chassis}

To accommodate four triptycene wheels, a new chassis based on a perylene subunit was necessary. Our synthetic strategy (Scheme 4) started from the synthesis of di(4-iodophenyl)cyclopentadienone obtained from a double Knoevenagel reaction between 1,3-di(4-iodophenyl)propan-2-one and acenaphthenequinone in the presence of potassium hydroxyde (step a).

Scheme 4. Synthesis of a 4-wheel nanocar. (a) $\mathrm{KOH}, \mathrm{MeOH}$; (b) 1,2-bis(3,5-di-tert-butylphenyl)acethylene, $\mathrm{Ph}-\mathrm{O}-\mathrm{Ph}$; (c) $\mathrm{FeCl}_{3} 25 \mathrm{eq}, \mathrm{CH}_{2} \mathrm{Cl}_{2}-\mathrm{CH}_{3} \mathrm{NO}_{2}(9: 1)$; (d) 9ethynyltriptycene 10 eq, $\mathrm{Pd}\left(\mathrm{PPh}_{3}\right)_{4} \quad 10 \%$, CuI $20 \%$, piperidine-THF $(1: 1)$.

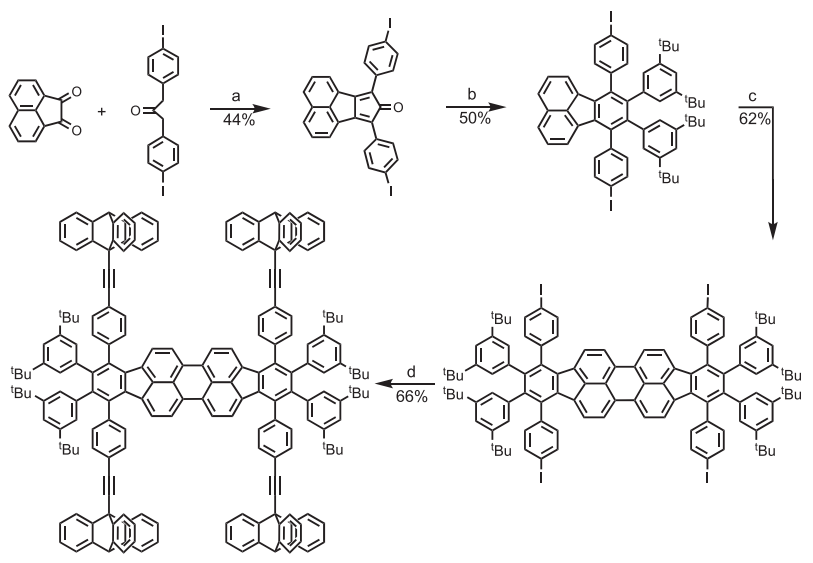

In the second step, a Diels-Alder reaction with 1,2-di(3,5di-tert-butylphenyl)acethylene gave, after aromatization by $\mathrm{CO}$ extrusion, the half-chassis (step b) which was dimerized via a Scholl coupling induced by Fe(III) as oxidant (step c). In the last step, four ethynyltriptycenyl wheels were attached via a quadruple Sonogashira coupling to give a planar 4-wheeled nanocar in $66 \%$ yield.

As expected, once deposited on $\mathrm{Au}(111)$, it proved very difficult to move such a planar nanovehicle due to its strong interaction of the polyaromatic chassis with the surface.

\subsection{A Nanocar Built on a Curved Polyaromatic Chassis}

The Scholl reaction is a coupling reaction between two arene compounds. It allows for increasing the number of cycles in the produced polyaromatic platform. With some modified precursors, it was possible to generate a highly-curved chassis. By replacing the 3,5-di-tert-butylphenyl fragments by 4-tertbutylphenyl groups, the same synthetic strategy used for the planar chassis gave an overcyclized perylene platform bearing six additional $\mathrm{C}-\mathrm{C}$ bonds as shown in bold on Scheme 5. By decreasing the number of tert-butyl groups, the planarity of contiguous phenyl rings became possible and consequently a higher number of Scholl-type oxidative coupling have been achieved. A geometry optimization of this curved chassis is presented in Scheme 5.

Scheme 5. Synthesis of a curved polyaromatic nanocar. (a) $\mathrm{Ph}-\mathrm{O}-$ Ph; (b) $\mathrm{FeCl}_{3} 25 \mathrm{eq}, \mathrm{CH}_{2} \mathrm{Cl}_{2}-\mathrm{CH}_{3} \mathrm{NO}_{2}$ (9: 1); (c) 9ethynyltriptycene 8 eq, $\mathrm{Pd}\left(\mathrm{PPh}_{3}\right)_{4} \quad 10 \%$, CuI $20 \%$, piperidine/THF (1:1). The additional carbon-carbon bonds obtained in the Scholl reaction are highlighted in bold.
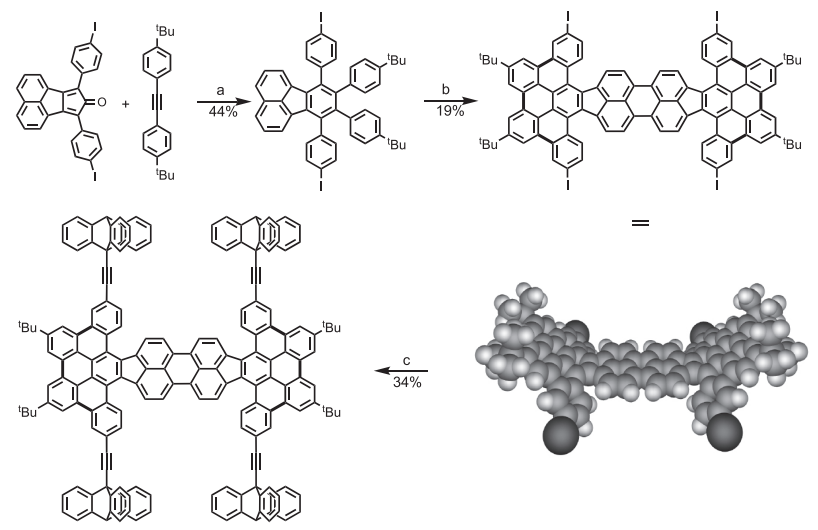

In the last step, the four ethynyltriptycene wheels were covalently attached via a quadruple Sonogashira coupling to successfully form the corresponding nanovehicle in 34\% yield. This low yield is a side effect of the solubility of the molecules containing a lower number of tert-butyl groups. This curvature can be explained by the presence of alternating five and six-membered rings like in fullerenes and at the extremities of carbon nanotubes.

This curved nanocar exhibits an intense dark green color and qualified for the first nanocar race ${ }^{32}$ which was organized in April 2017 in Toulouse (France).

After deposition on $\mathrm{Au}(111)$ by sublimation at 5K, STM manipulation of this curved nanocar gave a clearer image compared to the planar ones (Figure 2) with a brighter contrast for the four triptycene wheels. ${ }^{33}$ This is due to the reduced interactions of the curved polyaromatic chassis and this molecule has indeed shown a better mobility on an $\mathrm{Au}(111)$ surface when pushed or pulled.

\section{From Pushing to Electric-field Induced Motions}

On a surface, the pushing or pulling mode is historically the original and easiest way to move a molecule. ${ }^{34}$ However, this always needs a contact between the STM tip and the molecule, which limits the speed and could damage the nanovehicle. In our research on the rotation of molecular motors, after having first succeeded in achieving rotation unidirectionally with a piano-stool ruthenium complex at the single molecular scale by mechanically pushing the molecule, ${ }^{35}$ three years later we then succeeded to rotate a self-assembled monolayer of dipolar europium double-decker by an electric field induced by the STM tip. ${ }^{36}$ Electric field induced motion is possible not only on dipolar molecules. The rotation of a propeller shaped molecule without permanent dipole has also been achieved by positioning the tip close to the molecule. ${ }^{37} \mathrm{~A}$ unidirectional 

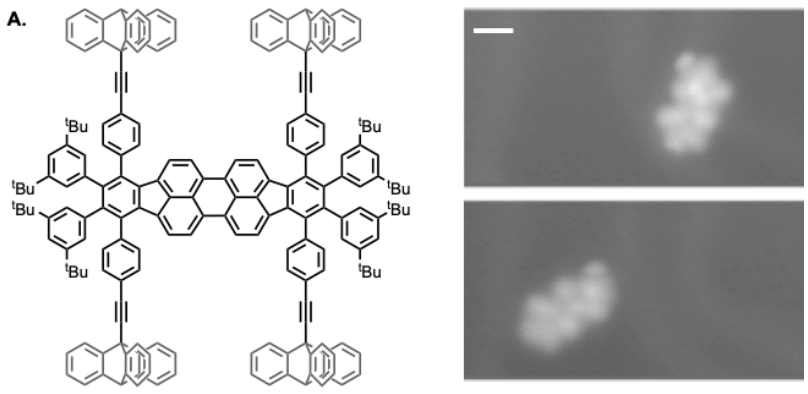

B.
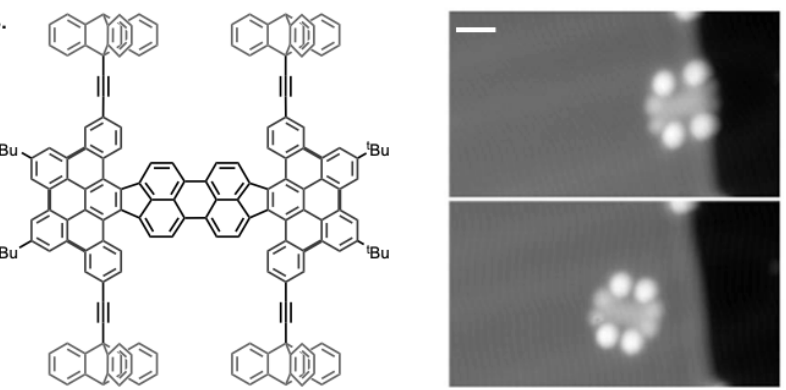

Figure 2. Chemical structures of the planar nanocar (A) and the curved nanocar (B) and the corresponding STM images showing the pushing of the molecule on a $\mathrm{Au}(111)$ surface. The white line corresponds to $1 \mathrm{~nm}$.

rotation of the propeller has been observed without any manipulation by the STM tip.

This efficient way to induce motion has been successfully used by two teams during the first nanocar race $^{38}$ and showed its superiority. This is the reason why we designed and synthesized a new family of dipolar nanocars.

\section{A Family of Dipolar Nanocars: Porphyrin-based Nanocars}

The design and synthesis of a new family of nanocars has been recently reported. ${ }^{39}$ Their architecture integrates a dipole, which can be tuned thanks to the strategic combination of donor and acceptor substituents at the 5- and 15-positions on its porphyrin backbone. Since the preparation of porphyrins is very versatile and can give rise to many types of substitution at the meso position, ${ }^{40}$ we substituted the two remaining meso positions with our ethynyltriptycene wheels.

In our design, we also need the porphyrin center to be metalated to avoid partial metalation on the metallic surfaces used. We selected a zinc(II) center to keep the required neutrality of the molecule and because it is well-known that porphyrins can form supramolecular architectures via axial coordination to a metal center ${ }^{41}$ giving our new nanocars the potential to load and carry cargo molecules.

Molecules possessing a permanent dipole moment can be manipulated thanks to their response to an electric field generated between the STM tip and the surface, but the relationship between the magnitude of the dipole moment and the mobility of the molecules still remains unclear. In this study, in order to clarify the relationship between the magnitude of the dipole moment and the mobility of molecules, we have designed a library of nine porphyrin-based nanocars in which various electron-donating and electron-withdrawing substituents are introduced as tuning units of their dipole moments. From the DFT calculations, it was found that the dipole moments of the nanocars can be tuned in the range of 5.0 to $9.9 \mathrm{D}$ by appro- priately selecting the substituents (Table 1). This showed that the introduction of electron-donating and -withdrawing groups as perturbation module units, enables us to tune the dipole moment precisely with a wide range of values.

Table 1. Dipole moment of nanocars evaluated by DFT calculation. All calculations were performed with the Gaussian09 suite of programs ${ }^{42}$ in vaccuo, using the WB97XD functional, taking into account long range interactions and dispersion corrections with the $6-31 \mathrm{G}^{*}$ basis set, a larger basis set than the $6-21 \mathrm{G}^{*}$ reported for previous similar compounds. ${ }^{43}$
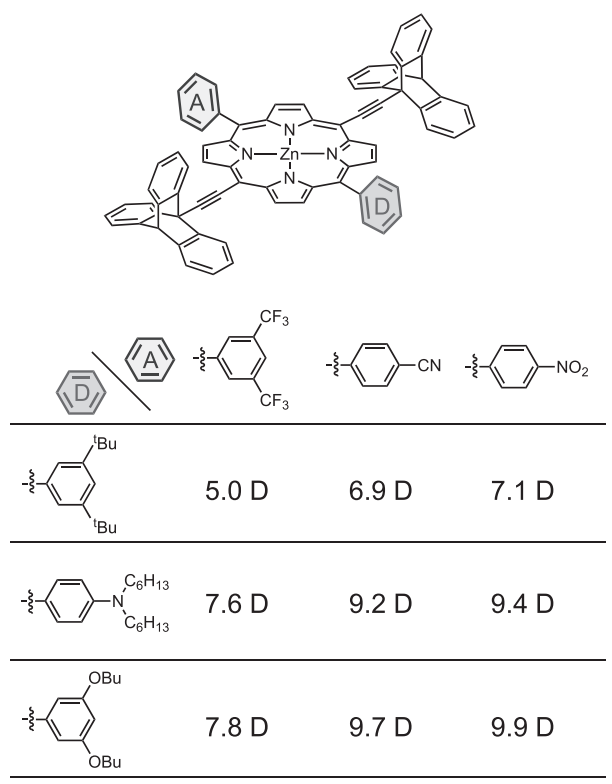

The synthetic strategy to access these nanocars is shown in Scheme 6 . The porphyrins with dissymmetrical substitutions at the 5 and 15 positions were synthesized by porphyrin ring formation using two kinds of aldehydes and dipyrromethane followed by the oxidation of the porphyrinogen intermediate as described by Lindsey. ${ }^{44}$ Then, bromination at the meso position of the porphyrins and coordination of the zinc were performed in two steps. Finally, the desired nanocar was obtained by Sonogashira coupling with ethynyltriptycene.

Among the synthesized nanocars, it has been possible to obtain the crystal structure for the system with 3,5-di(tertbutyl)phenyl group as electron donor and 4-cyanophenyl group as electron acceptor (Figure 3). In the crystal, a molecule of methanol, which was used as the crystallization solvent, was found to be coordinated to the axial position of the central zinc ion in a classical manner. ${ }^{45}$ This result illustrates the capacity of our nanocars to potentially serve as nanoplatforms to load and transport cargo molecules. We are now working on the construction of novel nanocars that can load and carry guest molecules on their chassis via various interactions based on appropriate design of their molecular structure.

\section{Conclusion and Perspectives}

In summary, we have presented the design and synthesis of various polyaromatic and porphyrin derivatives conceived by analogy with macroscopic nanocars in a technomimetic approach ${ }^{11}$ by mimicking a real car consisting of wheels and a chassis as their constitutive motifs.

As for the driving force of the movement of nanovehicles, we have evolved from direct pushing or pulling with an STM 
Scheme 6. Synthesis of porphyrin-based nanocars.
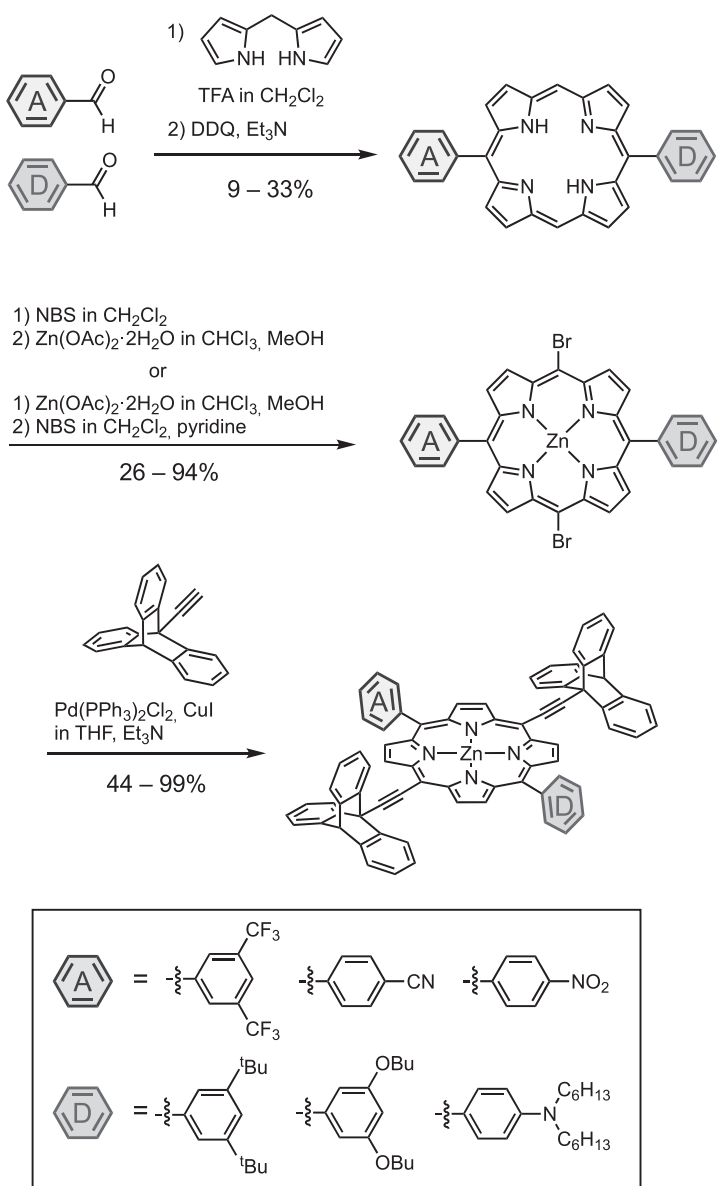

a)

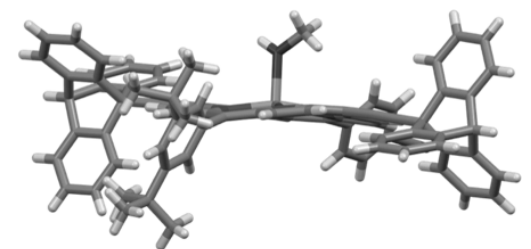

b)

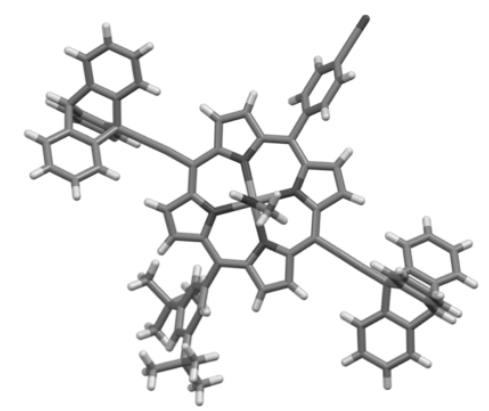

Figure 3. Single crystal X-ray structure of a porphyrin-based nanocar. a) Side view showing the coordination of a methanol molecule to the $\mathrm{Zn}$ center; b) Top view. Color code: $\mathrm{C}$, gray; $\mathrm{N}$, blue; $\mathrm{O}$, red; $\mathrm{Zn}$, mauve.

tip to non-contact addressing via the control of dipolar molecules with locally generated electric fields. Work is now underway to investigate the correlation between the amplitude of the dipole moment of the nanocar and their movability on surfaces. Establishing the laws describing the motion of dipolar molecules under the influence of an electric field induced by an STM tip is a challenge.
The more efficient nanocar, i.e. the molecule with the best compromise between its speed and controllability, will participate in the second nanocar race which could be organized in 2022.

\section{Acknowledgements}

This work was supported by the University Toulouse 3 Paul Sabatier and CNRS. It has received funding from the JSPS KAKENHI grant in aid for Scientific Research on Innovative Areas “Molecular Engine (No. 8006)" $18 \mathrm{H} 05419$ and the KAKENHI Grant-in-Aid for Challenging Research (20K21131). C.J.M. thanks the JSPS KAKENHI Grant-inAid for Early-Career Scientists (19K15312). We are also grateful to all of our collaborators and coworkers, particularly the students and post-docs, for their hard work and personal contributions and whose names appear in the references.

\section{References}

1) Sauvage, J.-P. Angew. Chem. Int. Ed. 2017, 56, 11080.

2) Stoddart, J. F. Angew. Chem. Int. Ed. 2017, 56, 11094

3) Feringa, B. L. Angew. Chem. Int. Ed. 2017, 56, 11060.

4) Ikeda, A.; Tsudera, T.; Shinkai, S. J. Org. Chem. 1997, 62, 3568.

5) Muraoka, T.; Kinbara, K.; Kobayashi, Y.; Aida, T. J. Am. Chem. Soc. 2003, 125, 5612 .

6) (a) Jimenez, M. C.; Dietrich-Buchecker, C.; Sauvage, J.-P. Angew. Chem. Int. Ed. 2000, 39, 3284. (b) Chambron, J.-C.; DietrichBuchecker, C.; Rapenne, G.; Sauvage, J.-P. Chirality 1998, 10, 125. (c) Romuald, C.; Busseron, E.; Coutrot, F. J. Org. Chem. 2010, 75, 6516. (d) Du, G.; Moulin, E.; Jouault, N.; Buhler, E.; Giuseppone, N. Angew. Chem. Int. Ed. 2012, 51, 12504.

7) Badjić, J. D.; Credi, A.; Silvi, S.; Stoddart, J. F. Science 2004, 303, 1845.

8) Kassem, S.; Lee, A. T. L.; Leigh, D. A.; Markevicius, A.; Solá, J. Nat. Chem. 2016, 8, 138.

9) (a) Kammerer, C.; Rapenne, G. Eur. J. Inorg. Chem. 2016, 2214. (b) Erbland, G.; Abid, S.; Gisbert, Y.; Saffon-Merceron, N.; Hashimoto, Y.; Andreoni, L.; Guérin, T.; Kammerer, C.; Rapenne, G. Chem. Eur. J. 2019, 25, 16328. (c) Gisbert, Y.; Abid, S.; Bertrand, G.; SaffonMerceron, N.; Kammerer, C.; Rapenne, G. Chem. Commun. 2019, 55, 14689. (d) Abid, S.; Gisbert, Y.; Kojima, M.; Saffon-Merceron, N.; Cuny, J.; Kammerer, C.; Rapenne, G. Chem. Sci. 2021, 12, 4709.

10) (a) Soe, W.-H.; Kleinwächter, M.; Kammerer, C.; Rapenne, G.; Joachim, C. J. Phys. Chem. C 2020, 124, 22625. (b) Au Yeung, K. H.; Kühne, T.; Eisenhut, F.; Kleinwächter, M.; Gisbert, Y.; Robles, R.; Lorente, N.; Cuniberti, G.; Joachim, C.; Rapenne, G.; Kammerer, C.; Moresco, F. J. Phys. Chem. Lett. 2020, 11, 6892

11) (a) Rapenne, G. Org. Biomol. Chem. 2005, 3, 1165. (b) Gakh, A. A. Molecular Devices: An Introduction to Technomimetics and Its Biological Applications; John Wiley \& Sons: Hoboken, NJ, 2018. (c) Kammerer, C.; Erbland, G.; Gisbert, Y.; Nishino, T.; Yasuhara, K.; Rapenne, G. Chem. Lett. 2019, 48, 299.

12) Jimenez-Bueno, G.; Rapenne, G. Tetrahedron Lett. 2003, 44, 6261

13) Nishino, T.; Martin, C. J.; Takeuchi, H.; Lim, F.; Yasuhara, K.; Gisbert, Y.; Abid, S.; Saffon-Merceron, N.; Kammerer C.; Rapenne, G. Chem. Eur. J. 2020, 26, 12010.

14) The second Nanocar Race has been planned in the Spring 2021 but due to the COVID-19 sanitary crisis, it was postponed to 2022. The precise date has not been fixed yet.

15) Gourdon, A. Eur. J. Org. Chem. 1998, 2797.

16) Chen, C. F.; Ma, Y. X. Iptycenes chemistry from synthesis to applications, Springer-Verlag, Berlin, Germany, 2013.

17) Joachim, C.; Moresco, F.; Rapenne, G.; Meyer, G. Nanotechnol. 2002, 13,330 .

18) (a) Jimenez-Bueno, G.; Rapenne, G. Tetrahedron Lett. 2003, 44, 6261. (b) Rapenne, G.; Jimenez-Bueno, G. Tetrahedron 2007, 63, 7018

19) Joachim, C.; Rapenne, G. ACS Nano 2013, 7, 11.

20) Shirai, Y.; Osgood, A. J.; Zhao, Y.; Kelly, K. F.; Tour, J. M. Nano Lett. 2005, 5, 2330 .

21) Morin, J.-F.; Sasaki, T.; Shirai, Y.; Guerrero, J. M.; Tour, J. M. J. Org. Chem. 2007, 72, 9481.

22) Vives, G.; Tour, J. M. Tetrahedron Lett. 2009, 50, 1427.

23) Chu, P. L. E.; Wang, L. Y.; Khatua, S.; Kolomeisky, A. B.; Link, S.; Tour, J. M. ACS Nano 2013, 7, 35. 
24) Kudernac, T.; Ruangsupapichat, N.; Parschau, M.; Maci, B.; Katsonis, N.; Harutyunyan, S. R.; Ernst, K. H.; Feringa, B. L. Nature 2011, 479, 208.

25) Jacquot de Rouville, H.-P.; Garbage, R.; Ample, F.; Nickel, A.; Meyer, J.; Moresco, F.; Joachim, C.; Rapenne, G. Chem. Eur. J. 2012, 18,8925 .

26) (a) Soe, W.-H.; Shirai, Y.; Durand, C.; Yonamine, Y.; Minami, K.; Bouju, X.; Kolmer, M.; Ariga, K.; Joachim, C.; Nakanishi, W. ACS Nano 2017, 11, 10357. (b) Durand, C.; Moresco, F.; Launay, J.-P.; Joachim, C. Eur. Phys. J. Appl. Phys. 2016, 76, 10001. (c) Pawlak, R.; Meier, T; Renaud, N.; Kisiel, M.; Hinaut, A.; Glatzel, T.; Sordes, D.; Durand, C.; Soe, W.-H.; Baratoff, A.; Joachim, C.; Housecroft, C. E.; Constable, E. C.; Meyer, E. ACS Nano 2017, 11, 9930.

27) Höger, S.; Bonrad, K. J. Org. Chem. 2000, 65, 2243.

28) Toyota, S. Chem. Rev. 2010, 110, 5398.

29) Grill, L.; Rieder, K. H.; Moresco, F.; Jimenez-Bueno, G.; Wang, C.; Rapenne, G.; Joachim, C. Surf. Sci. 2005, 584, 153

30) Grill, L.; Rieder, K. H.; Moresco, F.; Rapenne, G.; Stojkovic, S.; Bouju, X.; Joachim, C. Nat. Nanotechnol. 2007, 2, 95.

31) Jacquot de Rouville, H.-P.; Garbage, R.; Cook, R. E.; Pujol, A. R.; Sirven, A. M.; Rapenne, G. Chem. Eur. J. 2012, 18, 3023.

32) (a) Rapenne, G.; Joachim, C. Nat. Rev. Mater. 2017, 2, 17040. (b) Nanocar Race Official Website. Available online: http://nanocar-race. cnrs.fr/indexEnglish.php (accessed on $7^{\text {th }}$ April 2021).

33) Soe, W.-H.; Durand, C.; Gauthier, S.; Jacquot de Rouville, H.-P.; Kammerer, C.; Rapenne, G.; Joachim, C. Nanotechnology 2018, 29, 495401.

34) For early examples of mechanically-induced motions of molecules, see: (a) Beton, P. H.; Dunn, A. W.; Moriarty, P. Appl. Phys. Lett. 1995, 67, 1075. (b) Moresco, F.; Meyer, G.; Rieder, K. H.; Tang, H.; Gourdon, A.; Joachim, A. Appl. Phys. Lett. 2001, 78, 306. (c) Hla, S.-W. J. Vac. Sci. Technol. B 2005, 23, 1351.

35) Perera, U. G. E.; Ample, F.; Kersell, H.; Zhang, Y.; Vives, G.; Echeverria, J.; Grisolia, M.; Rapenne, G.; Joachim, C.; Hla, S.-W. Nat. Nanotechnol. 2013, 8, 46.

36) Zhang, Y.; Kersell, H.; Stefak, R.; Echeverria, J.; Iancu, V.; Perera, U. G. E.; Li, Y.; Deshpande, A.; Braun, K.-F.; Joachim, C.; Rapenne, G.; Hla, S.-W. Nat. Nanotechnol. 2016, 11, 706.

37) Zhang, Y.; Calupitan, J. P.; Rojas, T.; Tumbleson, R.; Erbland, G.; Kammerer, C.; Ajayi, T. M.; Wang, S.; Curtiss, L. A.; Ngo, A. T.; Ulloa, S. E.; Rapenne, G.; Hla, S. W. Nat. Commun. 2019, 10, 3742.

38) (a) Pawlak, R.; Meier, T. Nat. Nanotechnol. 2017, 12, 712. (b) Simpson, G. J.; García-López, V.; Petermeier, P.; Grill, L.; Tour, J. M. Nat. Nanotechnol. 2017, 12, 604

39) Nishino, T.; Martin, C. J.; Takeuchi, H.; Lim, F.; Yasuhara, K.; Gisbert, Y.; Abid, S.; Saffon-Merceron, N.; Kammerer, C.; Rapenne, G. Chem. Eur. J. 2020, 26, 12010.

40) (a) Chevalier, F.; Geier, G. R.; Lindsey, J. S. J. Porphyr. Phthalocyanines 2002, 6, 186. (b) Hu, G.; Kang, H. S.; Mandal, A. K.; Roy, A.; Kirmaier, C.; Bocian, D. F.; Holten, D.; Lindsey, J. S. RSC Adv. 2018, 8, 23854.

41) Bols, P. S.; Anderson, H. L. Acc. Chem. Res. 2018, 51, 2083

42) Frisch, M. J.; Trucks, G. W.; Schlegel, H. B.; Scuseria, G. E.; Robb, M. A.; Cheeseman, J. R.; Scalmani, G.; Barone, V.; Mennucci, B.; Petersson, G. A.; Nakatsuji, H.; Caricato, M.; Li, X.; Hratchian, H. P.; Izmaylov, A. F.; Bloino, J.; Zheng, G.; Sonnenberg, J. L.; Hada, M.; Ehara, M.; Toyota, K.; Fukuda, R.; Hasegawa, J.; Ishida, M.; Nakajima, T; Honda, Y; Kitao, O; Nakai, H; Vreven, T; Montgomery Jr, J. A.; Peralta, J. E.; Ogliaro, F.; Bearpark, M.; Heyd, J. J.; Brothers, E.; Kudin, K. N.; Staroverov, V. N.; Kobayashi, R.; Normand, J.; Raghavachari, K.; Rendell, A.; Burant, J. C.; Iyengar, S. S.; Tomasi, J.; Cossi, M.; Rega, N.; Millam, J. M.; Klene, M.; Knox, J. E.; Cross, J. B.; Bakken, V.; Adamo, C.; Jaramillo, J.; Gomperts, R.; Stratmann, R. E.; Yazyev, O.; Austin, A. J.; Cammi, R.; Pomelli, C.; Ochterski, J. W.; Martin, R. L.; Morokuma, K.; Zakrzewski, V. G.; Voth, G. A.; Salvador, P.; Dannenberg, J. J.; Dapprich, S.; Daniels, A. D.; Farkas, Ö.; Foresman, J. B.; Ortiz, J. V.; Cioslowski, J.; Fox, D. J. Gaussian 09 Revision A. 02, Gaussian Inc. Wallingford CT, 2009.

43) Verykios, A.; Papadakis, M.; Soultati, A.; Skoulikidou, M.-C.; Papaioannou, G.; Gardelis, S.; Petsalakis, I. D.; Theodorakopoulos, G.; Petropoulos, V.; Palilis, L. C.; Fakis, M.; Vainos, N. A.; Alexandropoulos, D.; Davazoglou, D.; Pistolis, G.; Argitis, P.; Coutsolelos, A. G.; Vasilopoulou, M. ACS Omega 2018, 3, 10008.

44) Geier III, G. R.; Lindsey, J. S. Tetrahedron 2004, 60, 11435.

45) Darling, S. L.; Stulz, E.; Feeder, N.; Bampos, N.; Sanders, J. K. M. New J. Chem. 2000, 24, 261

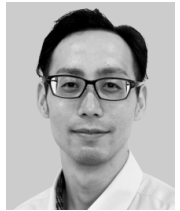

Toshio Nishino obtained his Ph.D. degree at Nagoya University under the supervision of Prof. Kentaro Tanaka in 2016. He worked two years (2016-2018) as a postdoctoral fellow in the group of Prof. Toshiharu Teranishi at Kyoto University. In 2018, he moved to Nara Institute of Science and Technology (NAIST) as an Assistant Professor. His current research interests are the construction of integrated molecular machine systems and visualization of movement of molecular machines on a macroscopic scale.

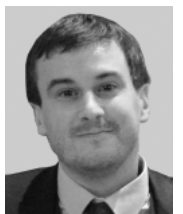

Colin John Martin obtained his Ph.D. in chemistry in 2011 from Trinity College Dublin (Ireland), under the supervision of Prof. Sylvia Draper, on the synthesis, spectroscopic and electrochemical investigation of thienyl derivatives of polyaromatic hydrocarbons. He spent three and half years as a postdoctoral fellow in the group of Prof. Edwin Constable in the Inorganic Chemistry Department, Universität Basel, Switzerland, working on novel chemical and microscopic strategies for the development of photovoltaic cells. In 2016 he joined the NAISTCEMES International Collaborative laboratory as a Specially Appointed Assistant Professor. His current research interests are in the development of new light responsive molecules.

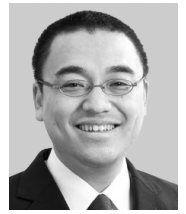

Kazuma Yasuhara received his Ph.D. degree from Nara Institute of Science and Technology (NAIST) under the supervision of Professor Jun-ichi Kikichi in 2008. He became an Assistant Professor in the Graduate School of Materials Science, NAIST in 2009. During 2013 to 2014, he joined the group of Prof. William F. DeGrado in the Department of Pharmaceutical Chemistry, University of California, San Francisco as a Visiting Assistant Professor. In 2018, he was promoted Associate Professor in the Graduate School of Science and Technology, NAIST. His current research interests are biomimetic design of bio-functional materials as well as biological application of technomimetic molecules.

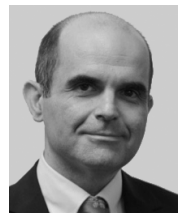

Gwénaël Rapenne received his Ph.D. in 1998 from Louis Pasteur University (Strasbourg) under the supervision of Prof. Jean-Pierre Sauvage and Dr Christiane Dietrich-Buchecker working on the synthesis and resolution of double helices and molecular knots. After spending one year as a Lavoisier postdoctoral fellow working on Fullerenes with Prof. F. Diederich at ETH Zürich, he joined the University Paul Sabatier of Toulouse as an Assistant Professor to work in the field of single molecular machines in the NanoSciences Group at CEMES-CNRS and has been promoted Full Professor in 2011. From 2018 he is also Professor in Nara Institute of Science and Technology (cross-appointment) where he is the head of the Biomimetic and Technomimetic Molecular Science Laboratory. 